\title{
Self-limiting low-temperature growth of crystalline AlN thin films by plasma-enhanced atomic layer deposition
}

\author{
Cagla Ozgit, Inci Donmez, Mustafa Alevli, Necmi Biyikli* \\ UNAM - Institute of Materials Science and Nanotechnology, Bilkent University, Ankara 06800, Turkey
}

\section{A R T I C L E I N F O}

Article history:

Received 30 April 2011

Received in revised form 21 November 2011

Accepted 28 November 2011

Available online 4 December 2011

\section{Keywords:}

Aluminum nitride

Thin film

Atomic layer deposition

Self-limiting growth

Trimethylaluminum

Wurtzite

\begin{abstract}
A B S T R A C T
We report on the self-limiting growth and characterization of aluminum nitride (AlN) thin films. AlN films were deposited by plasma-enhanced atomic layer deposition on various substrates using trimethylaluminum (TMA) and ammonia $\left(\mathrm{NH}_{3}\right)$. At $185^{\circ} \mathrm{C}$, deposition rate saturated for TMA and $\mathrm{NH}_{3}$ doses starting from 0.05 and $40 \mathrm{~s}$, respectively. Saturative surface reactions between TMA and $\mathrm{NH}_{3}$ resulted in a constant growth rate of $\sim 0.86 \AA$ /cycle from 100 to $200{ }^{\circ} \mathrm{C}$. Within this temperature range, film thickness increased linearly with the number of deposition cycles. At higher temperatures $\left(\geq 225^{\circ} \mathrm{C}\right)$ deposition rate increased with temperature. Chemical composition and bonding states of the films deposited at $185^{\circ} \mathrm{C}$ were investigated by Xray photoelectron spectroscopy. High resolution $\mathrm{Al} 2 \mathrm{p}$ and $\mathrm{N} 1 \mathrm{~s}$ spectra confirmed the presence of AlN with peaks located at 73.02 and $396.07 \mathrm{eV}$, respectively. Films deposited at $185^{\circ} \mathrm{C}$ were polycrystalline with a hexagonal wurtzite structure regardless of the substrate selection as determined by grazing incidence X-ray diffraction. High-resolution transmission electron microscopy images of the AlN thin films deposited on Si (100) and glass substrates revealed a microstructure consisting of nanometer sized crystallites. Films exhibited an optical band edge at $\sim 5.8 \mathrm{eV}$ and an optical transmittance of $>95 \%$ in the visible region of the spectrum.
\end{abstract}

(c) 2011 Elsevier B.V. All rights reserved.

\section{Introduction}

Aluminum nitride (AIN) attracts considerable interest since it offers a unique combination of material properties including wide and direct band gap of $6.2 \mathrm{eV}$, good dielectric properties, piezoelectric response, high thermal conductivity, as well as stability and low expansion at high temperatures [1]. When processed in the form of thin film, AlN finds applications as buffer layers for the growth of high quality materials [2,3], insulators for thin film transistors [4], interfacial layers for metal oxide semiconductor field effect transistors [5,6] and high-electron mobility transistors [7], surface passivation layers for surface channel field effect transistors [8] and sensitive GaAs structures [9], transparent substrates [10] and active layers [11] for extreme UV light-emitting diodes and photodetectors. AlN films are also used in the fabrication of surface acoustic wave devices [12], mechanical resonators [13], piezoelectric transducers [14], and gas sensors [15].

Metal-organic chemical vapor deposition (MOCVD) [16], molecular beam epitaxy (MBE) [17], pulsed laser deposition [18], and sputtering [19] are the most common techniques employed for the growth of AlN. Although MOCVD offers the most efficient process due to its ability to deposit high quality materials with significant growth rates, deposition of

\footnotetext{
* Corresponding author. Tel.: +90 312290 3556; fax: +90 3122664365 . E-mail address: biyikli@unam.bilkent.edu.tr (N. Biyikli).
}

AlN requires high temperatures $\left(>1000{ }^{\circ} \mathrm{C}\right)$ [16]. Use of temperaturesensitive device layers (e.g. In-rich $\operatorname{In}_{x} \mathrm{Ga}_{1}{ }_{-} \mathrm{N}$ [20]) and substrates (e.g. flexible polymeric substrates), therefore, necessitates the adaptation of low-temperature growth methods.

Atomic layer deposition (ALD) is a special type of lowtemperature chemical vapor deposition, in which the substrate surface is exposed to sequential pulses of two or more precursors separated by purging periods [21,22]. Unless decomposition of the precursor occurs, each pulse leads to surface reactions that terminate after the adsorption of a single monolayer. When compared to other low-temperature methods, ALD stands out with its self-limiting growth mechanism, which enables the deposition of highly conformal thin films with sub-nanometer thickness control.

AlN growth by ALD has been studied by several research groups [23-29]. Lee et al. [23] reported plasma-enhanced ALD (PEALD) of AlN at $350{ }^{\circ} \mathrm{C}$ using aluminum chloride $\left(\mathrm{AlCl}_{3}\right)$ and $\mathrm{NH}_{3} / \mathrm{H}_{2}$ plasma. Growth rate of this process saturated at $\sim 0.42 \AA /$ cycle, resulting with films composed of microcrystallites of wurtzite (100) in an amorphous AlN matrix [24]. Thermal [25,26], plasma-enhanced [26], and UV-assisted [27] ALD of AlN using trimethylaluminum (TMA) and ammonia $\left(\mathrm{NH}_{3}\right)$ have been studied within the temperature ranges of $320-470,250-470$, and $240-370{ }^{\circ} \mathrm{C}$, respectively - however, no self-limiting growth behavior was observed. This was explained by Riihela et al. [25] by the fact that surface reactions between TMA and $\mathrm{NH}_{3}$ occur with reasonable rates only at temperatures where TMA self-decomposition takes place. Recently, Bosund et al. [28] 
used the same precursors to produce AIN films by PEALD at temperatures ranging from 100 to $300{ }^{\circ} \mathrm{C}$. Films deposited in their study were amorphous except for the one grown at $300{ }^{\circ} \mathrm{C}$. Kim et al. [29], on the other hand, have reported remote plasma ALD of amorphous AIN thin films using TMA and $\mathrm{N}_{2} / \mathrm{H}_{2}$ plasma. In their study, growth rate saturated at $\sim 1.25 \AA /$ cycle within the range of $100-400{ }^{\circ} \mathrm{C}$ and then decreased with increasing temperature.

Here we report on the self-limiting growth of crystalline AlN thin films at low temperatures by PEALD using TMA and $\mathrm{NH}_{3}$ as the aluminum and nitrogen precursors, respectively. Process parameters including TMA pulse time, $\mathrm{NH}_{3}$ flow rate and duration, purge time, deposition temperature, and plasma power were investigated. Structural, optical and surface characterization results of the films deposited at $185^{\circ} \mathrm{C}$ are also presented.

\section{Experimental details}

AlN thin films were deposited on pre-cleaned substrates at temperatures ranging from 100 to $500{ }^{\circ} \mathrm{C}$. Depositions were carried out in a Fiji F200-LL ALD reactor (Cambridge Nanotech) with a base pressure of $30 \mathrm{~Pa}$, using $\mathrm{Ar}$ as the carrier gas. Unless stated otherwise, $\mathrm{NH}_{3}$ plasma flow rate and power were $50 \mathrm{sccm}$ and $300 \mathrm{~W}$, respectively. System was purged for $10 \mathrm{~s}$ after each precursor exposure. Prior to depositions, Si (100), Si (111), c-plane sapphire, MOCVD-grown GaN on c-plane sapphire, and glass (Pyrex) substrates were cleaned by sequential ultrasonic agitation in 2-propanol, acetone, methanol, and deionized (DI) water. Solvent cleaned silicon substrates were further dipped into dilute hydrofluoric acid solution for $\sim 1 \mathrm{~min}$, then rinsed with DI water and dried with $\mathrm{N}_{2}$.

Ellipsometric spectra of the films were recorded in the wavelength range of $300-1000 \mathrm{~nm}$ at three angles of incidence $\left(65^{\circ}, 70^{\circ}\right.$, and $\left.75^{\circ}\right)$ by using a variable angle spectroscopic ellipsometer (J.A. Woollam). Optical constants of the $\sim 33 \mathrm{~nm}$ thick AlN thin films deposited by thermal ALD at $450{ }^{\circ} \mathrm{C}$ and PEALD at $185^{\circ} \mathrm{C}$ were modeled by the Cauchy dispersion function, and used for the estimation of ALD- and PEALD-grown film thicknesses, respectively. Measurement results were confirmed by cross-sectional transmission electron microscopy (TEM). Deposition rates were calculated by dividing film thicknesses to the number of ALD cycles.

Chemical composition and bonding states of the films were determined by X-ray photoelectron spectroscopy (XPS) using Thermo Scientific K-Alpha spectrometer with a monochromatized Al K $\alpha$ X-ray source. Sputter depth profiling was carried out with a beam of $\mathrm{Ar}$ ions having an acceleration voltage and spot size of $1 \mathrm{kV}$ and $400 \mu \mathrm{m}$, respectively. Grazing-incidence X-ray diffraction (GIXRD) measurements were performed in a PanAnalytical X'Pert PRO MRD diffractometer using $\mathrm{Cu} K \alpha$ radiation. FEI Tecnai G2 F30 transmission electron microscope at an operating voltage of $300 \mathrm{kV}$ was used for the imaging of samples prepared by FEI Nova 600i Nanolab focused ion beam (FIB) system. Samples were prepared at an acceleration voltage of $30 \mathrm{kV}$, using various beam currents ranging from $50 \mathrm{pA}$ to $21 \mathrm{nA}$. Damage layer was removed by FIB milling at beam voltages of 5 and $2 \mathrm{kV}$. An atomic force microscope (AFM, Asylum Research MFP-3D) operating in the contact mode was used to reveal surface morphology of the AlN thin films. Room temperature transmission and absorption measurements were performed with a UV-VIS spectrophotometer (Varian Cary 100).

\section{Results and discussion}

Thermal ALD experiments were carried out within the temperature range of $300-500{ }^{\circ} \mathrm{C}$, where one cycle consisted of $0.5 \mathrm{~s}$ TMA pulse/10 s purge/7.5 s (200 sccm) $\mathrm{NH}_{3}$ flow/10 s purge. Fig. 1(a) shows the deposition rates of AlN thin films at different growth temperatures. Although deposition rates of 0.07 and $0.14 \AA$ /cycle were estimated for 300 and $350{ }^{\circ} \mathrm{C}$, respectively, XPS studies have revealed that there is no AlN deposition at $300{ }^{\circ} \mathrm{C}$. For $350{ }^{\circ} \mathrm{C}$, on the other hand, only trace amount of AlN was detected. These results indicate that deposition of AlN with practical rates starts at $400{ }^{\circ} \mathrm{C}$ with $0.8 \AA$ /cycle. For higher temperatures, growth rate increased with temperature and reached a value of $2 \AA / \mathrm{cycle}$ at $500{ }^{\circ} \mathrm{C}$. Deposition rate as a function of precursor doses is also given in Fig. 1(a). TMA pulse time and $\mathrm{NH}_{3}$ flow duration (flow rate $=150 \mathrm{sccm}$ ) were increased simultaneously from $(0.1 \mathrm{~s}, 1 \mathrm{~s})$ to $(2 \mathrm{~s}, 20 \mathrm{~s})$ at $450{ }^{\circ} \mathrm{C}$. Deposition rate increased with the increasing amount of precursors. Saturation was not observed neither as a function of the temperature nor the precursor doses. Fig. 1(b) shows the effect of purge time on deposition rate at $450{ }^{\circ} \mathrm{C}$. Deposition rate decreased from 0.95 to $0.79 \AA /$ cycle as the purge time increased from 2 to $10 \mathrm{~s}$, and remained constant at this value for purge times up to $40 \mathrm{~s}$. Purge time of $10 \mathrm{~s}$ used in thermal ALD experiments therefore avoids overlapping of the precursor pulses and does not have any effect on the saturation behavior. These results are in agreement with those reported in the literature $[25,26]$, where no self-limiting growth behavior was observed due to the fact that surface reactions between TMA and $\mathrm{NH}_{3}$ occur at temperatures where TMA self-decomposition takes place. Self-limiting growth of AlN is therefore not possible with thermal ALD using TMA and $\mathrm{NH}_{3}$ precursors. In order to achieve self-limiting surface reactions, TMA (i.e., $\left.\mathrm{Al}\left(\mathrm{CH}_{3}\right)_{3}\right)$ self-decomposition must be avoided by the use of lower deposition temperatures. In this respect, high temperatures needed for the $\mathrm{NH}_{3}$ reaction can be lowered by using a plasma-assisted process.

Saturation curves of aluminum and nitrogen precursors obtained by PEALD at $185^{\circ} \mathrm{C}$ are shown in Fig. 2. For the TMA saturation curve, $\mathrm{NH}_{3}$ flow rate, duration, and plasma power were kept constant at $50 \mathrm{sccm}, 20 \mathrm{~s}$, and $300 \mathrm{~W}$, respectively. Deposition rate increased
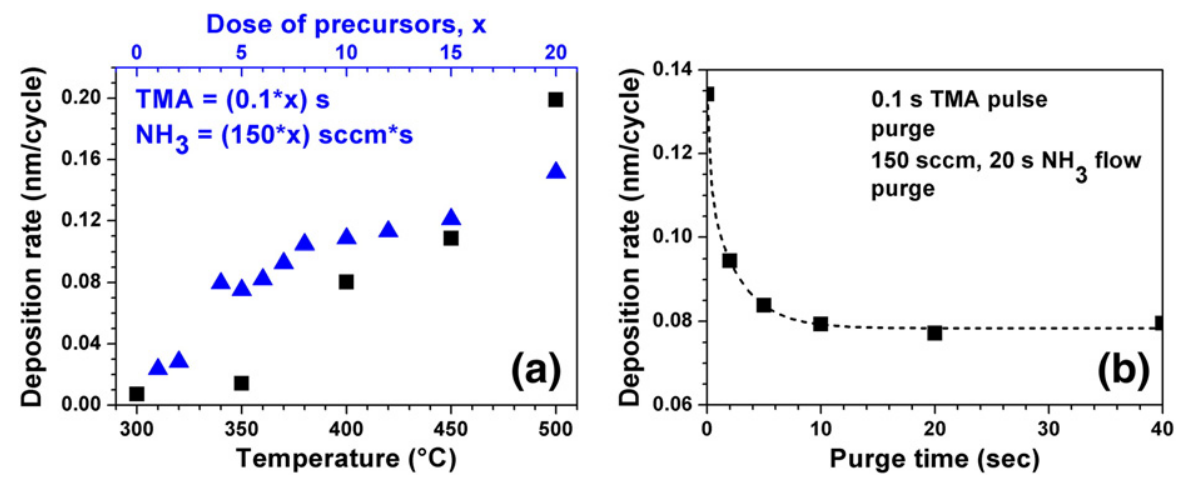

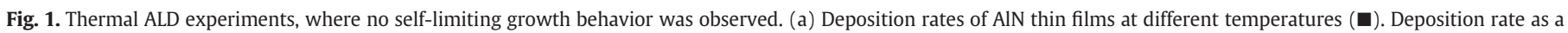
function of TMA and $\mathrm{NH}_{3}$ doses at $450{ }^{\circ} \mathrm{C}(\mathbf{\Delta})$. (b) Deposition rate as a function of purge time at $450{ }^{\circ} \mathrm{C}$. 


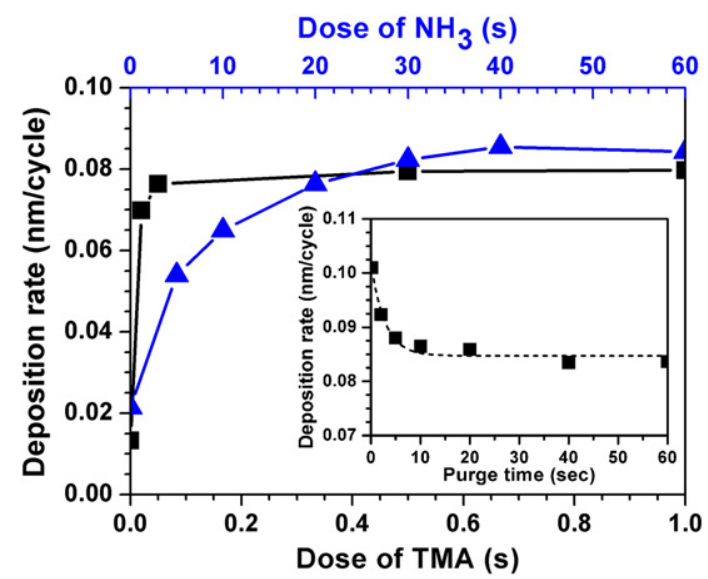

Fig. 2. Precursor saturation curves at $185^{\circ} \mathrm{C}: \mathrm{NH}_{3}$ dose was kept constant at $20 \mathrm{~s}$ for the TMA saturation curve ( $\mathbf{\square}$ ), and TMA dose was kept constant at $0.05 \mathrm{~s}$ for the $\mathrm{NH}_{3}$ saturation curve ( $\boldsymbol{\Delta})$. (Inset) Deposition rate as a function of purge time: TMA dose and $\mathrm{NH}_{3}$ flow duration were constant at 0.1 and $40 \mathrm{~s}$, respectively.

with increasing TMA dose until $0.05 \mathrm{~s}$, where growth rate saturated at $\sim 0.76 \AA$ /cycle. For the $\mathrm{NH}_{3}$ saturation curve, TMA dose was constant at $0.05 \mathrm{~s}$ and $\mathrm{NH}_{3}$ flow duration was varied with constant flow rate
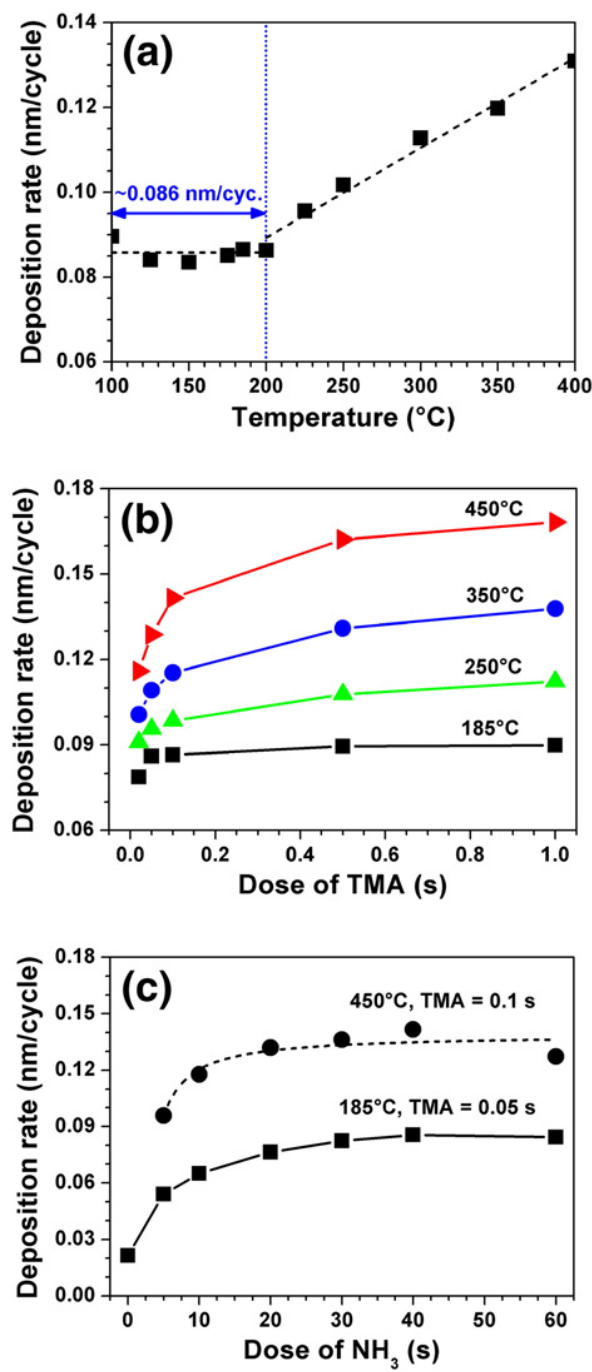

Fig. 3. (a) Deposition rates of AlN thin films at different temperatures. (b) TMA saturation curves at $185,250,350$, and $450^{\circ} \mathrm{C}$, where $\mathrm{NH}_{3}$ flow duration was kept constant at $40 \mathrm{~s}$. (c) $\mathrm{NH}_{3}$ saturation curves at 185 and $450{ }^{\circ} \mathrm{C}$. and plasma power (50 sccm, $300 \mathrm{~W}$ ). Deposition rate increased with increasing $\mathrm{NH}_{3}$ flow duration until maximum rate of $\sim 0.86 \AA$ /cycle was obtained at $40 \mathrm{~s}$. Increasing $\mathrm{NH}_{3}$ dose to $60 \mathrm{~s}$ did not increase the deposition rate. The effect of purge time on deposition rate was also studied at $185{ }^{\circ} \mathrm{C}$ (inset of Fig. 2). Deposition rate decreased from 1.01 to $0.86 \AA$ /cycle as the purge time increased from 0.2 to $10 \mathrm{~s}$. For longer purge times, deposition rate remained almost constant. Increased deposition rates at short purge times are due to insufficient purging, where one precursor is introduced into the reactor before the other one is completely removed. These results show that $10 \mathrm{~s}$ purge time is already a good estimation for $185^{\circ} \mathrm{C}$ and does not require any further optimization.

Deposition rates of AlN thin films at different temperatures are given in Fig. 3(a). For these experiments, 100 cycle depositions were carried out with cycles consisting of $0.1 \mathrm{~s}$ TMA pulse $/ 10 \mathrm{~s}$ purge/40 s ( $50 \mathrm{sccm}, 300 \mathrm{~W}$ ) $\mathrm{NH}_{3}$ flow/10 s purge. Deposition rate remained constant at $\sim 0.86 \AA$ /cycle for temperatures up to $200{ }^{\circ} \mathrm{C}$, and then increased with temperature. Temperature dependency of the deposition rate, observed within the range of $200-400{ }^{\circ} \mathrm{C}$, may be due to the effect of temperature on the number and type of reactive sites present on the surface before and after the chemisorption, or the effect of temperature on the preferred reaction mechanisms [22]. Self-decomposition of TMA molecules may also be responsible from the increasing growth rate with temperature, however this is unlikely since the lowest temperature reported for the decomposition of TMA is $\sim 300{ }^{\circ} \mathrm{C}[30]$. In order to investigate this further, TMA and $\mathrm{NH}_{3}$ saturation characteristics were studied at higher deposition temperatures. Fig. 3(b) shows TMA saturation curves at 185, 250, 350 , and $450{ }^{\circ} \mathrm{C}$. As the temperature increased, curves gradually deviated from the self-limiting behavior. $\mathrm{NH}_{3}$ saturation curves at 185 and $450{ }^{\circ} \mathrm{C}$ are given in Fig. 3(c). As the temperature increased from 185 to $450{ }^{\circ} \mathrm{C}$, deposition rate increased without any deviation from the self-limiting behavior. Assuming that the decomposition of TMA does not occur until $300^{\circ} \mathrm{C}$, the deviation observed in TMA saturation curve at $250{ }^{\circ} \mathrm{C}$ might be due to the increase in saturation TMA dose. TMA dose needed for the saturation of $\mathrm{NH}_{3}$-terminated surface may increase with temperature if the number of reactive sites or sticking coefficient has temperature dependency [31].

Film thickness vs. number of deposition cycles is given in Fig. 4. Film thickness increases linearly with increasing number of cycles, confirming that the deposition rate is constant at $185^{\circ} \mathrm{C}$. Results also suggest that deposition starts immediately with the first cycle, without any incubation period. Inset of Fig. 4 shows the deposition rate as a function of plasma power at $185^{\circ} \mathrm{C}$. As the plasma power increased from 50 to $100 \mathrm{~W}$, deposition rate increased from 0.66 to

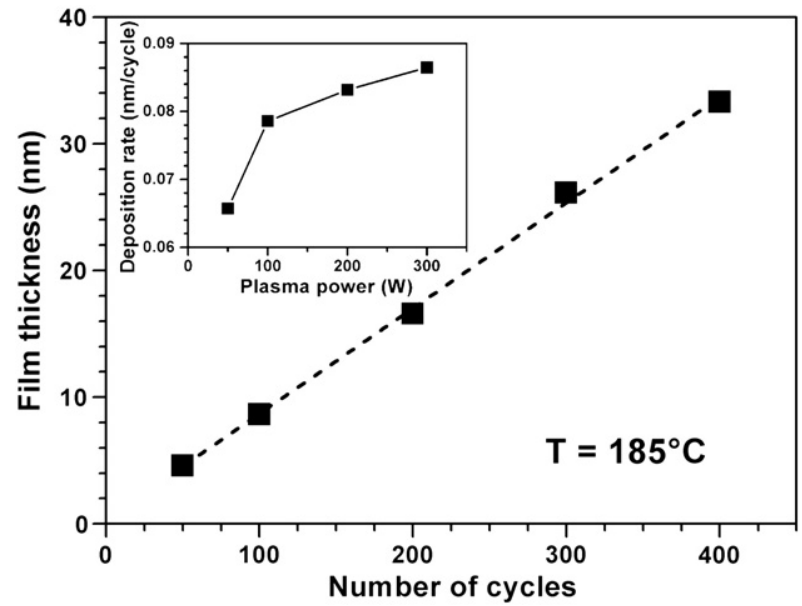

Fig. 4. Film thickness vs. number of deposition cycles. (Inset) Deposition rate of AlN as a function of plasma power. 
$0.79 \AA /$ cycle. As the power further increased to $300 \mathrm{~W}$ deposition rate increased to $0.86 \AA$ /cycle. These results indicate that dissociation efficiency of $\mathrm{NH}_{3}$ and consequently deposition rate of AlN can be further increased by the use of higher plasma powers, i.e. $>300 \mathrm{~W}$.

When compared to $\mathrm{AlCl}_{3}$, use of TMA as the aluminum precursor resulted in higher deposition rates at lower temperatures. Moreover, saturation was achieved at much lower doses. Use of metal organic precursors (such as trimethyl metal compounds) instead of metal chlorides also avoids the formation of corrosive byproduct (i.e., hydrogen chloride) and hence increases the lifetime of deposition system.

Compositional characterization of $\sim 100 \mathrm{~nm}$ thick AlN film deposited on $\mathrm{Si}(100)$ at $185^{\circ} \mathrm{C}$ was carried out by using XPS. Survey scans detected peaks of aluminum, nitrogen, oxygen, and carbon. Fig. 5(a) is the compositional depth profile showing that atomic concentrations of $\mathrm{Al}$ and $\mathrm{N}$ are constant in the bulk film. Although $\mathrm{O}$ concentration is high (35 at.\%) at the film surface, it decays rapidly within the first $120 \mathrm{~s}$. At $600 \mathrm{~s}$, concentrations of $\mathrm{Al}, \mathrm{N}$, and $\mathrm{O}$ are 59.8, 37.6, and 2.6 at.\%, respectively. Carbon is detected only at the film surface and there are no $\mathrm{C}$ impurities in the bulk film, indicating that efficient removal of methyl groups from TMA was achieved by the use of $\mathrm{NH}_{3}$ plasma.

0 1s high resolution XPS scan given in Fig. 5(b) represents the film surface, whereas $\mathrm{Al} 2 \mathrm{p}$ and $\mathrm{N}$ 1s scans given in Fig. 5(c) and (d) refer to bulk film (etch time $=150 \mathrm{~s}$ ). 0 1s scan was fitted by two peaks located at 529.96 and $531.46 \mathrm{eV}$, corresponding to $\mathrm{Al}-\mathrm{O}-\mathrm{N}$ [32] and $\mathrm{Al}-\mathrm{O}$ [33] bonds, respectively. Results, which indicate oxidation at the film surface, are similar to those reported in the literature for air-exposed AlN thin films deposited by plasma source MBE [33]. Al 2 p data was fitted with a single peak at $73.02 \mathrm{eV}$ (Fig. 5(c)), which is assigned to the $\mathrm{Al}-\mathrm{N}$ bond [33,34]. Additional information about the chemical bonding states in the films is provided by the $\mathrm{N} 1 \mathrm{~s}$ spectrum that was fitted by two peaks as shown in Fig. 5(d). N 1s peak at $396.07 \mathrm{eV}$, which is assigned to the $\mathrm{N}-\mathrm{Al}$ bond [35], confirms the presence of AlN. Peak at $398.0 \mathrm{eV}(\mathrm{N}-\mathrm{Al}-\mathrm{O}$ bond [33]), on the other hand, corresponds to the $<5$ at.\% $\mathrm{O}$ present in the bulk film.

AlN thin films deposited at $185^{\circ} \mathrm{C}$ were polycrystalline as determined by GIXRD. Fig. 6 shows the GIXRD pattern of $\sim 100 \mathrm{~nm}$ thick

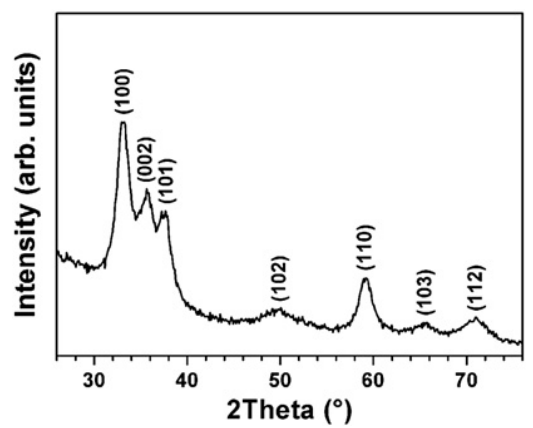

Fig. 6. GIXRD pattern of $\sim 100 \mathrm{~nm}$ thick AIN thin film deposited on Si (100). Film is polycrystalline with a hexagonal wurtzite structure.

AlN film on Si (100) substrate, where (100), (002), (101), (102), (110), (103), and (112) reflections of the hexagonal wurtzite phase were observed. Similar patterns were obtained for the films deposited on Si (111), c-plane sapphire, MOCVD-grown GaN on c-plane sapphire, and glass substrates, with only difference being the more pronounced intensity of (100) reflection in the case of sapphire and $\mathrm{GaN} /$ sapphire substrates.

Fig. 7(a) is the cross-sectional TEM image of the AlN film deposited on Si (100) at $185^{\circ} \mathrm{C}$. Film thickness was measured as $95.9 \mathrm{~nm}$ from this image, which is in good agreement with the results obtained by ellipsometry. Fig. 7(b) and (c) are the high-resolution TEM (HR-TEM) images of the same sample, showing a film microstructure consisting of nanometer sized crystallites. Selected area electron diffraction (SAED) pattern of this film is also given in the inset of Fig. 7(b). In this pattern, reciprocal lattice points correspond to the diamond lattice of Si substrate. Diffraction rings, on the other hand, refer to AlN thin film and indicate a polycrystalline nature. HR-TEM image of the polycrystalline AlN thin film deposited on amorphous glass substrate is given in Fig. 7(d). SAED pattern of this sample consists of two polycrystalline diffraction rings (not shown here).

Fig. 8(a) shows the surface morphology of $\sim 33 \mathrm{~nm}$ thick AlN film deposited on Si (100) substrate. Root-mean-square (rms) roughness
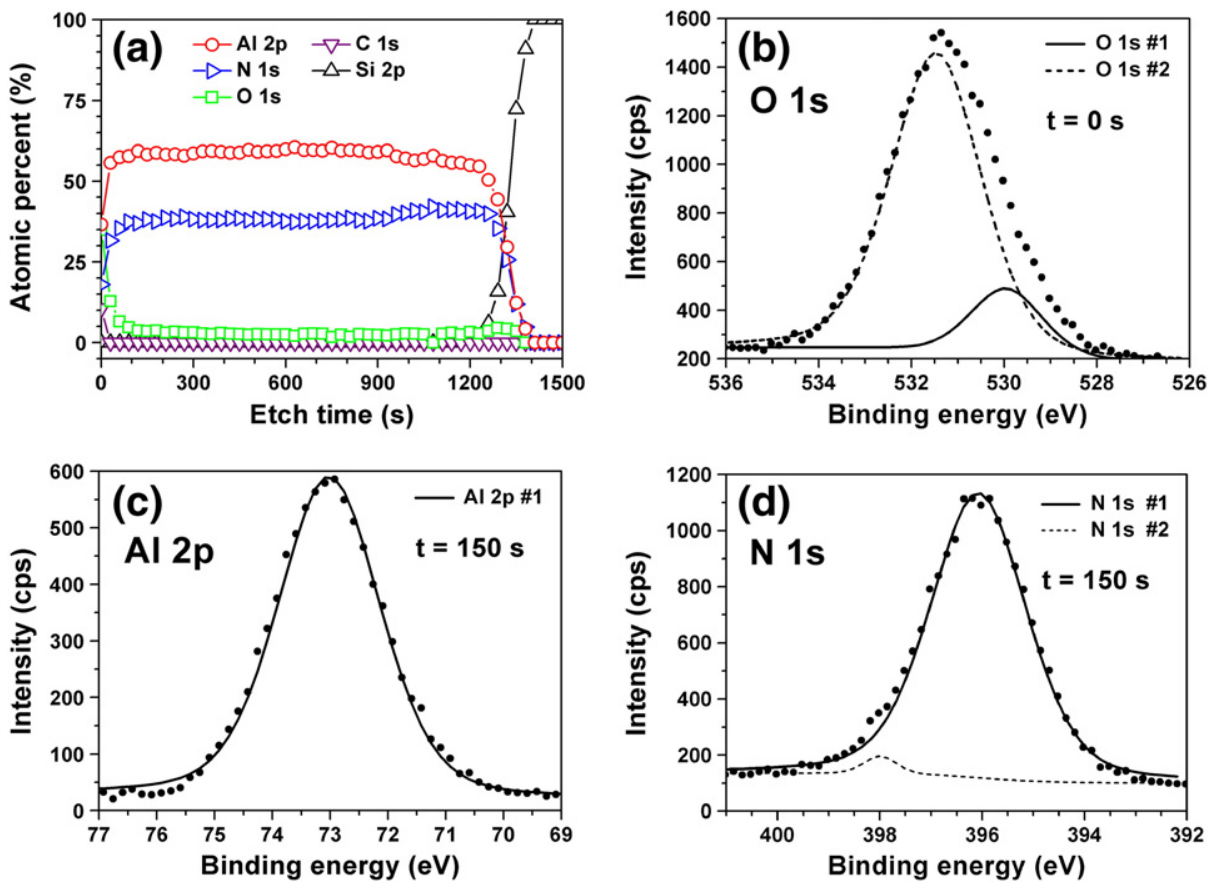

Fig. 5. (a) Compositional depth profile of $\sim 100 \mathrm{~nm}$ thick AIN thin film. (b) $01 \mathrm{~s}$, (c) Al 2p, and (d) N $1 \mathrm{~s}$ high resolution XPS scans, 
(a)

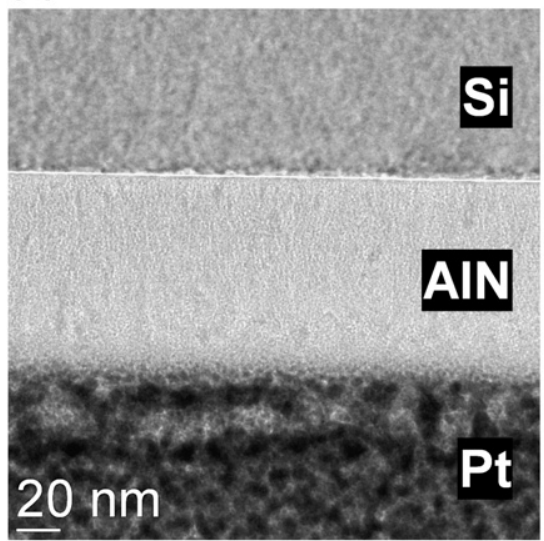

(c)

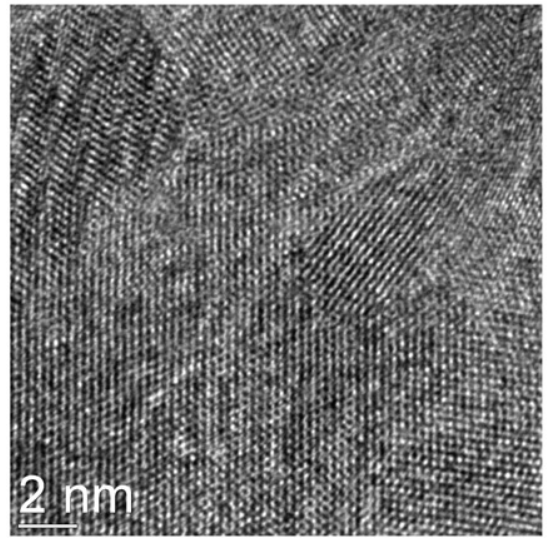

(b)

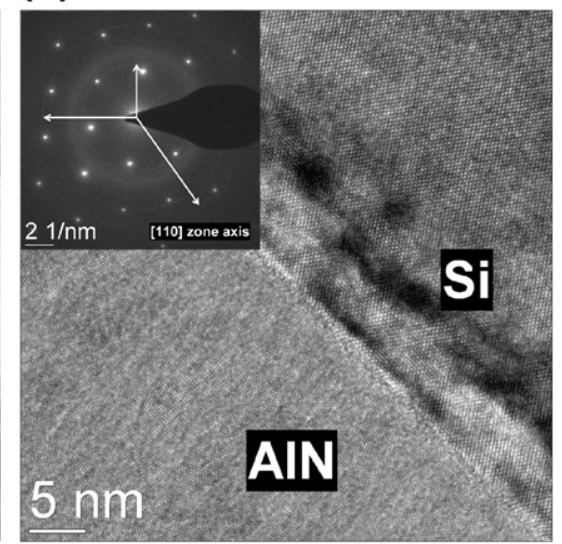

(d)

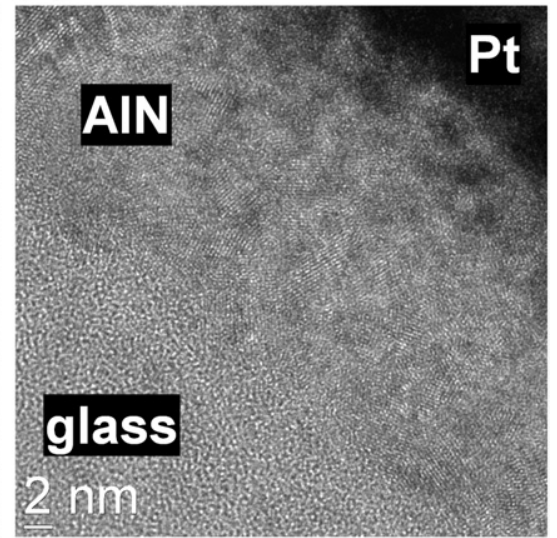

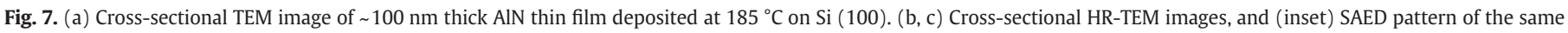
sample. (d) Cross-sectional HR-TEM image of AIN thin film deposited on glass substrate.

of the film was measured as $0.32 \mathrm{~nm}$ from a $2 \mu \mathrm{m} \times 2 \mu \mathrm{m}$ scan area. Rms roughness values of the AlN films deposited on GaN/sapphire (Fig. 8(b)) and sapphire substrates were 0.42 and $0.51 \mathrm{~nm}$, respectively. AFM image revealing the surface morphology of $\sim 100 \mathrm{~nm}$ thick AlN film deposited on Si (100) substrate is given in Fig. 8(c). As the film thickness increased from $\sim 33$ to $\sim 100 \mathrm{~nm}$, rms roughness increased from 0.32 to $1.25 \mathrm{~nm}$.

Refractive index and extinction coefficient of AlN film deposited at $185^{\circ} \mathrm{C}$ are shown in Fig. 9(a). Refractive index, which is 2.15 at $270 \mathrm{~nm}$, decreases to 1.88 at $1000 \mathrm{~nm}$. These values are in good agreement with those reported in the literature for polycrystalline AlN thin films [36]. Extinction coefficient $(k)$, which is $\sim 0.03$ at $270 \mathrm{~nm}$, decreases rapidly within the wavelength range of $270-335 \mathrm{~nm}$. For higher wavelengths $k$ is almost zero, indicating that films are transparent in this spectral region. Room temperature transmission spectrum, which is corrected for the substrate and spectrometer response characteristics, is given in Fig. 9(b) for $\sim 100 \mathrm{~nm}$ thick AlN film deposited at $185^{\circ} \mathrm{C}$ on double-side polished sapphire. Transmission increases with wavelength within the range of $185-350 \mathrm{~nm}$, reaches to $95 \%$ at $350 \mathrm{~nm}$ and remains $>95 \%$ until $3 \mu \mathrm{m}$ (not shown here). A pronounced reduction of the transmission signal within $235-300 \mathrm{~nm}$ is also noteworthy. This absorption band, centered at $\sim 255.5 \mathrm{~nm}(4.86 \mathrm{eV})$, is attributed to the oxygen- or vacancy-related defects [37]. Since AlN is a direct band gap material and absorption coefficient is directly proportional to the wavevector value, the square of the product of absorption vs. incident photon wavelength is shown in the inset of Fig. 9(b) in order to better determine the optical band edge (absorption edge) [38]. Experimental absorption spectrum of the sample shows that absorption decreases rapidly in the UV spectral range and becomes insignificant in the visible region. A straight line fitted through the measured data (dashed line shown in the inset of Fig. 9(b)) intersects the abscissa at $\sim 5.8 \mathrm{eV}$, revealing the optical band edge of AlN thin films deposited by PEALD.

\section{Conclusion}

In this study, we have deposited crystalline AlN thin films by PEALD at temperatures as low as $100{ }^{\circ} \mathrm{C}$. Constant growth rate of $\sim 0.86 \AA$ /cycle was observed from 100 to $200{ }^{\circ} \mathrm{C}$. For higher temperatures $\left(\geq 225^{\circ} \mathrm{C}\right)$ deposition rate increased with temperature. At $185^{\circ} \mathrm{C}$, film thicknesses increased linearly with the number of deposition cycles and no incubation behavior was observed. AlN thin films deposited at $185^{\circ} \mathrm{C}$ were polycrystalline with a hexagonal wurtzite structure regardless of the substrate selection as determined by GIXRD and HR-TEM. Films exhibited an optical band edge at $\sim 5.8 \mathrm{eV}$ and high transparency in the visible region of the spectrum.

\section{Acknowledgments}

This work was performed at UNAM supported by the State Planning Organization (DPT) of Turkey through the National Nanotechnology Research Center Project. Authors would like to acknowledge K. Mizrak and M. Guler from UNAM for TEM sample preparation and HR-TEM measurements, respectively. Authors would also like to acknowledge E. Deguns from Cambridge Nanotech Inc. for his useful comments and suggestions. GaN/sapphire templates were provided by U. Ozgur and H. Morkoc from Virginia Commonwealth University. N.B. acknowledges support from Marie Curie International Reintegration Grant (Grant \# PIRG05-GA-2009-249196). M.A. acknowledges the financial support from TUBITAK (Project No: 232.01-660/ 4835). 
(a)

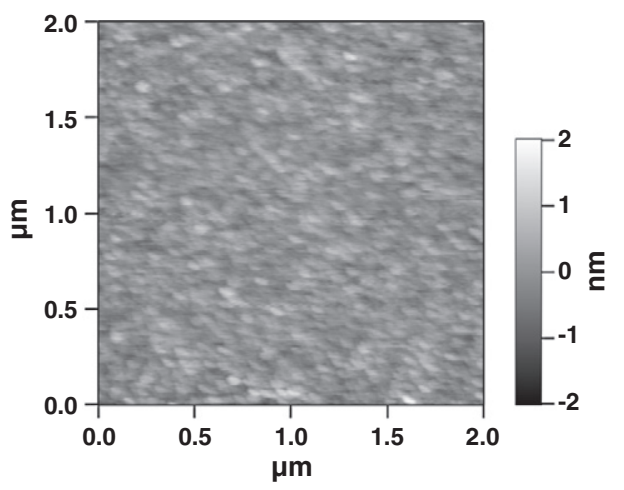

(b)

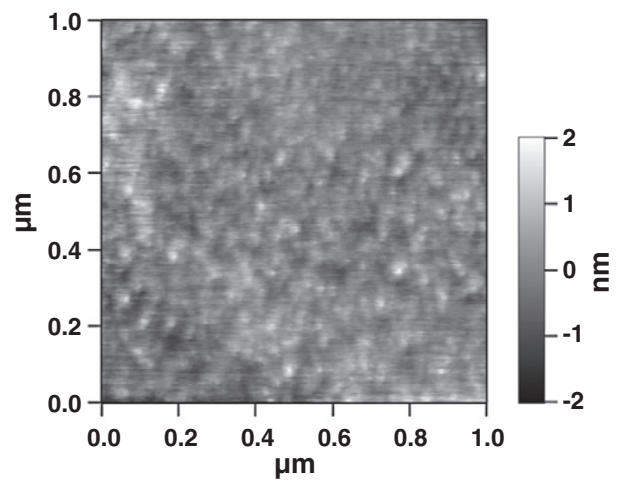

(c)

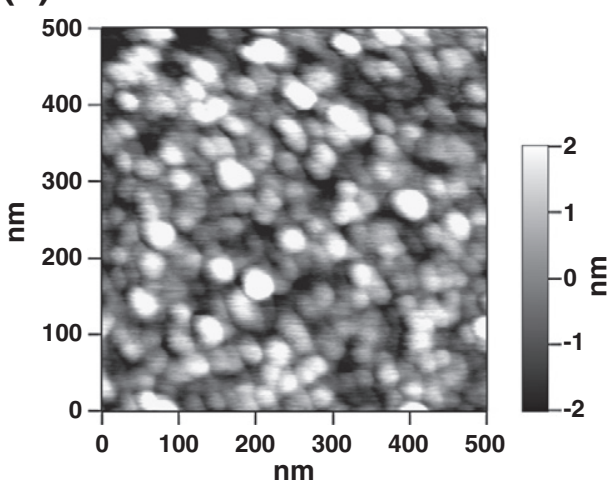

Fig. 8. Surface morphology of $\sim 33 \mathrm{~nm}$ thick AlN thin films deposited at $185^{\circ} \mathrm{C}$ on (a) $\mathrm{Si}$ (100), and (b) MOCVD-grown GaN on c-plane sapphire. (c) Surface morphology of $\sim 100 \mathrm{~nm}$ thick AlN film deposited at $185^{\circ} \mathrm{C}$ on $\mathrm{Si}(100)$

\section{References}

[1] S.C. Jain, M. Willander, J. Narayan, R. Van Overstraeten, J. Appl. Phys. 87 (2000) 965.

[2] H. Amano, N. Sawaki, I. Akasaki, Y. Toyoda, Appl. Phys. Lett. 48 (1986) 353.

[3] H. Lu, W.J. Schaff, J. Hwang, H. Wu, G. Koley, L.F. Eastman, Appl. Phys. Lett. 79 (2001) 1489.

[4] M.M. De Souza, S. Jejurikar, K.P. Adhi, Appl. Phys. Lett. 92 (2008) 093509.

[5] K.H. Kim, R.G. Gordon, A. Ritenour, D.A. Antoniadis, Appl. Phys. Lett. 90 (2007) 212104

[6] D. Shahrjerdi, T. Rotter, G. Balakrishnan, D. Huffaker, E. Tutuc, S.K. Banerjee, IEEE Electron Device Lett. 29 (2008) 557.

[7] L. Shen, S. Heikman, B. Moran, R. Coffie, N.-Q. Zhang, D. Buttari, I.P. Smorchkova, S. Keller, S.P. DenBaars, U.K. Mishra, IEEE Electron Device Lett. 22 (2001) 457.

[8] D. Kueck, P. Leber, A. Schmidt, G. Speranza, E. Kohn, Diam. Relat. Mater. 19 (2010) (2010) 932.

[9] M. Bosund, P. Mattila, A. Aierken, T. Hakkarainen, H. Koskenvaara, M. Sopanen, V.-M. Airaksinen, H. Lipsanen, Appl. Surf. Sci. 256 (2010) 7434.

[10] A. Hanlon, P.M. Pattison, J.F. Kaeding, R. Sharma, P. Fini, S. Nakamura, Jpn. J. Appl. Phys. 42 (2003) L628.

[11] Y. Taniyasu, M. Kasu, T. Makimoto, Nature 441 (2006) 325.

[12] T. Aubert, O. Elmazria, B. Assouar, L. Bouvot, M. Oudich, Appl. Phys. Lett. 96 (2010) 203503.

[13] A.N. Cleland, M. Pophristic, I. Ferguson, Appl. Phys. Lett. 79 (2001) 2070.

[14] M.-A. Dubois, P. Muralt, Appl. Phys. Lett. 74 (1999) 3032.

[15] F. Serina, K.Y.S. Ng, C. Huang, G.W. Auner, L. Rimai, R. Naik, Appl. Phys. Lett. 79 (2001) 3350.

[16] Z. Chen, S. Newman, D. Brown, R. Chung, S. Keller, U.K. Mishra, S.P. Denbaars, S. Nakamura, Appl. Phys. Lett. 93 (2008) 191906.

[17] L. Lahourcade, E. Bellet-Amalric, E. Monroy, M. Abouzaid, P. Ruterana, Appl. Phys. Lett. 90 (2007) 131909.

[18] J. Baek, J. Ma, M.F. Becker, J.W. Keto, D. Kovar, Thin Solid Films 515 (2007) 7096.

[19] C. Mirpuri, S. Xu, J.D. Long, K. Ostrikov, J. Appl. Phys. 101 (2007) 024312.

[20] M. Alevli, G. Durkaya, A. Weerasekara, A.G.U. Perera, N. Dietz, W. Fenwick, V. Woods, I. Ferguson, Appl. Phys. Lett. 89 (2006) 112119.

[21] M. Leskela, M. Ritala, Thin Solid Films 409 (2002) 138

[22] R.L. Puurunen, J. Appl. Phys. 97 (2005) 121301.

[23] Y.J. Lee, S.-W. Kang, Thin Solid Films 446 (2004) 227.

[24] Y.J. Lee, J. Cryst. Growth 266 (2004) 568.

[25] D. Riihela, M. Ritala, R. Matero, M. Leskela, J. Jokinen, P. Haussalo, Chem. Vap. Deposition 2 (1996) 277.

[26] X. Liu, S. Ramanathan, E Lee, TE Seidel, Mater. Res. Soc. Symp. Proc. 811 (2004) D1.9.1.

[27] D. Eom, S.Y. No, C.S. Hwang, H.J. Kim, J. Electrochem. Soc. 153 (2006) C229.

[28] M. Bosund, T. Sajavaara, M. Laitinen, T. Huhtio, M. Putkonen, V.-M. Airaksinen, H. Lipsanen, Appl. Surf. Sci. 257 (2011) 7827.

[29] K.-H. Kim, N.-W. Kwak, S.H. Lee, Electron. Mater. Lett. 5 (2009) 83.

[30] R.L. Puurunen, M. Lindblad, A. Root, A.O.I. Krause, Phys. Chem. Chem. Phys. 3 (2001) 1093.

[31] M. Rose, JW. Bartha, I. Endler, Appl. Surf. Sci. 256 (2010) 3778.

[32] C.C. Wang, M.C. Chiu, M.H. Shiao, F.S. Shieu, J. Electrochem. Soc. 151 (2004) F252.

[33] L. Rosenberger, R. Baird, E. McCullen, G. Auner, G. Shreve, Surf. Interface Anal. 40 (2008) 1254.

[34] D. Manova, V. Dimitrova, W. Fukarek, D. Karpuzov, Surf. Coat. Technol. 106 (1998) 205

[35] H.M. Liao, R.N.S. Sodhi, T.W. Coyle, J. Vac. Sci. Technol., A 11 (1993) 2681.

[36] H.C. Barshilia, B. Deepthi, K.S. Rajam, Thin Solid Films 516 (2008) 4168.

[37] M. Strassburg, J. Senawiratne, N. Dietz, U. Haboeck, A. Hoffmann, V. Noveski, R. Dalmau, R. Schlesser, Z. Sitar, J. Appl. Phys. 96 (2004) 5870.

[38] P. Lu, R. Collazo, R.F. Dalmau, G. Durkaya, N. Dietz, Z. Sitar, Appl. Phys. Lett. 93 (2008) 131922.
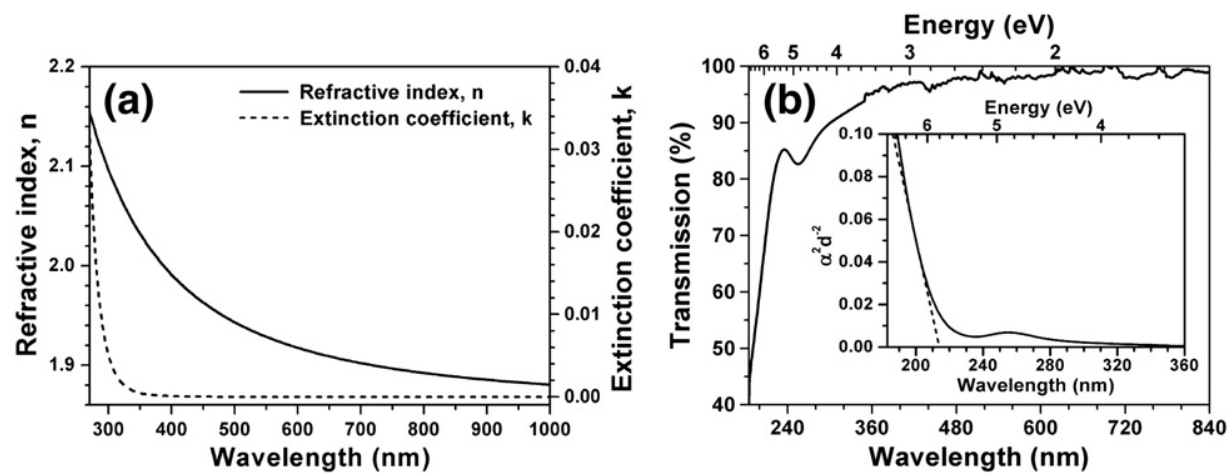

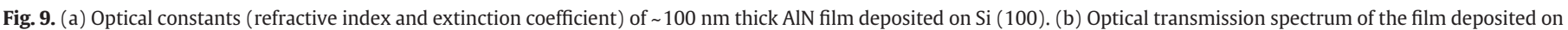
double-side polished sapphire. (Inset) Absorption spectrum of the same sample. 